\title{
Interpreter and Aboriginal Liaison Officer identity construction and positioning
}

\author{
Maria Karidakis \\ The University of Melbourne
}

\begin{abstract}
This study employs small story theory (Bamberg, 2006; Bamberg \& Georgakopoulou, 2008; Georgakopoulou, 2006, 2015, 2017) and narrative positioning analysis (Bamberg \& Georgakopoulou, 2008) to explore stories that are told by interpreters of Aboriginal languages and Aboriginal Liaison Officers (ALOs) when they discuss how they do their work and the challenges they face when interpreting for Aboriginal and Torres Strait Islander patients in hospital settings. Findings indicate that the interpreters and ALOs draw on stories to contribute their understanding of complexities of interpreting for Aboriginal patients and do so through the multiple, shifting positions they attribute to themselves as other social actors in the stories they narrate. These positions are reinforced in the ongoing interaction but are also located across the dataset, illustrating that capital- $D$ discourses or master narratives are invoked to frame the role, skills and attributes of the professionals in this study.
\end{abstract}

Keywords: small story research, narrative inquiry, narrative positioning analysis, interpreting, sociolinguistics

\section{Introduction}

This study adopts the small story approach (Bamberg, 2006; Bamberg \& Georgakopoulou, 2008; Georgakopoulou, 2006, 2015, 2017) and narrative positioning analysis (Bamberg \& Georgakopoulou, 2008) to explore how spontaneously produced stories are embedded within the professional practice of interpreters of Aboriginal languages and Aboriginal Liaison Officers (ALOs). These stories emerged as the participants stepped outside the prototypical question-answer format of research interviews to make a particular point more salient. Such stories have the potential to showcase how identities are constructed in situ and "are extremely valuable for showing how identity gets renegotiated and reconstructed in and through social interaction" (Freeman, 2007, p.156). 
This study also uses narrative positioning analysis in order to explore how interpreters and ALOs perform and co-construct their professional identities in narrative activities. The multiple, shifting positions the interpreters and ALOs adopt as they construct various identities, brings to the fore a range of capital- $D$ discourses pertaining to communication differences and challenges that medical interpreters and ALOs encounter as they interpret for Aboriginal patients or facilitate communication during the medical encounter. Here I adopt Gee's (1999, p.127) distinction between small- $d$ discourses and capital- $D$ discourses. The former refers to stretches of written or oral language in use and the latter is used to characterise "ways of being in the world, or forms of life which integrate words, acts, values, beliefs, attitudes, and social identities." The relationship between small- $d$ discourses and capital- $D$ discourses is not one-directional, small to big; rather capital-D discourses often frame and determine how individual instances of language in use are carried out. This distinction is important as it recognises the interrelationships between social relations, social identities, contexts, and specific situations of language use (Gee, 1999).

The following sections on small story and identity construction shed light on the methodology employed in this study. Firstly, the literature on small stories is drawn on to facilitate the identification of small stories in the dataset as a number of stories offered by the participants were fragmentary accounts of professional experience, habitual narratives or hypothetical narratives (Bamberg, 2006; Bamberg \& Georgakopoulou, 2008, p.382; Georgakopoulou, 2006, 2007). Secondly, the background literature on identity construction feeds into the discussion on Bamberg and Georgakopoulou's (2008) narrative positioning analysis, illustrating that the local construction of identity emerges in the turn-by-turn interaction but wider assumptions about identity can also be made by pinpointing how the participants in the study index the social work in their talk.

\section{Small stories and big stories}

Building on previous research into conversational storytelling, Bamberg and Georgakopoulou developed the small story "functionalist-informed" approach to narrative and identity analysis (Jefferson, 1978; Goodwin, 1986; Ochs \& Capps, 2001; Bamberg, 2006; Bamberg \& Georgakopoulou, 2008, p.382; Georgakopoulou, 2006, 2007). Small story research emerged as a counter response to prevailing models of narrative studies that:

a. defined narrative restrictively and on the basis of textual criteria; 
b. privileged a specific type of narrative, in particular the long, relatively uninterrupted, teller-led accounts of past events or of one's life story, typically elicited in research interview situations (Georgakopoulou, 2015, p.255).

A distinction was initially drawn between big and small stories; the former refers to "the grander narratives we tell ourselves, the big retrospectives [or life stories] elicited form interviews" (Watson, 2007, p.371); and the latter, small stories, are those that "present fragmentation and open-endedness of tellings, exceeding the confines of a single speech event and resisting a neat categorization of beginning middle - end" (Georgakopoulou, 2016, p.302). As such, small stories involve the analysis of "a gamut of under-represented and a-typical narrative activities, such as tellings of ongoing events, future or hypothetical events, or shared (known) events, but also allusions to tellings, deferrals of tellings, and refusals to tell" (Georgakopoulou, 2006, p.130). Small stories emerge within talk-in-interaction and are often co-constructed between tellers and audience who share some common knowledge and experience. It is important to note that Bamberg and Georgakopoulou did not set out to establish a rigid dichotomy between big and small stories but recognise "the pluralism, heterogeneity, and productive coexistence of narrative activities, big and small, in the same event, by the same teller, and so on" (Georgakopoulou, 2015, p.256). Thus, the small story approach lends itself to research that explores "how people use small stories in their interactive engagements to construct a sense of who they are, while big story research analyses the stories as representations of world and identities" (Bamberg \& Georgakopoulou, 2008, p.382). Small- $d$ discourses and capital- $D$ discourses have the potential to offer a micro-and a macro-perspective on the analysis of small stories. For instance, small- $d$ discourses refer to micro practices of interaction and the processes through which social actors construct knowledge, emotions and identities and these discourses feed into capital- $D$ discourses, or "the general societal contextual conditions" that speakers invoke to make sense of who they are (Bamberg, De Fina, \& Schiffrin, 2011, p.181). In effect speakers "choose the means by which they construct their identities vis-à-vis others as well as vis-à-vis dominant discourses and master narratives" (De Fina, Schiffrin, \& Bamberg, 2006, p.7).

\section{Identity construction}

How identity is enacted and communicated has been the focus of much work that examines identity processes such as "indexicality" (Silverstein, 1976/1980). Indexicality is referred to as "the mechanism whereby identity is constituted" (Bucholtz 
\& Hall, 2005, p.593) and helps to illustrate how linguistic forms, such as deictics and personal pronouns, may be employed to construct identity positions. There are several means of identity construction including making overt references to identity categories and drawing on pragmatic processes like implicature and presuppositions (Bucholtz \& Hall, 2005). Other means of constructing identity involve taking a stance or what Du Bois (2007, pp.139, 163) refers to as a "linguistically articulated form of social action" where speakers evaluate something and subsequently position themselves to align or not align with the listener. Closely related to indexicality is "local occasioning" (Antaki \& Widdicombe, 1998). The notion of local occasioning encapsulates the idea that the way that identity is presented or ascribed is dependent on the context in which the interaction takes place but also functions to shape that context. In this way, identities are made relevant for subsequent talk (Van Dijk, 2011). As Johnstone (2008, p.133) explains, indexicality "can point to pre-existing social meaning, but the use of an indexical can also create social meaning". In this sense, on one level, the local construction of the self can be traced in the turn-by-turn interaction and on another level, broader assumptions about identity can be drawn by examining how the participant in an interaction indexes the social world in their talk. This is in line with interactionally oriented trends in narrative analysis, where the primary focus is a detailed observation of speakers' local interactions and the ways in which discursive categories are negotiated and generated. For instance, Wortham (2001, p. 63) illustrates that due to the "socio-indexical" nature of language, narrators do not have to "explicitly represent their points, but instead they adopt positions by juxtaposing and inflecting the voices of various characters". Thus, narrators may animate the voices of characters and such animations are locally indexed prosodically and or lexically and often align the characters with a specific social group or assign specific social roles or positions to them (Wortham, 2001).

Apart from being socially situated, identity is also a "relational and dialogical process" (De Fina, 2011, p. 271). De Fina (2011, p. 271) elaborates on these processes by pointing out that "[i]ndividuals and collectivities express and negotiate their identities by occupying social and verbal spaces that are charted in oppositions or complementarities with others". Bamberg (2011, pp.3-7) builds on this idea by illustrating that the process of active engagement in the construction of self and identity is navigated or managed between what he calls "three dilemmatic spaces" or challenges that storytellers are faced with: firstly, the dilemma of constructing "sameness of a sense of self across time in the face of constant change"; secondly, "the establishment of a synchronic connection between sameness and difference (between self and other)"; and thirdly, "the management of agency of the self in the world". Each of these dilemmatic spaces seeks to provide an answer to the question "who am I?" and poses some challenge for identity work. The 
first dilemmatic space is negotiated by "sorting out what events qualify as formative or transformative for the emergence of identity". In this way, we can examine diachronically how an individual's identity evolves by negotiating between "constancy and change". The second dilemmatic space is negotiated by synchronically differentiating between sameness and differences in relation to self and others. In a narrative, this is the space where tellers position themselves vis-à-vis other characters and through the act of juxtaposing their selves with others, tellers are able to showcase their uniqueness. The third dilemmatic space relates to the management of agency in terms of whether it rests within the self or within contextual and social forces.

Bamberg (2011, p. 6) asserts that these dilemmatic spaces are closely related to both identity and the self in that "identity takes off from the continuity/change dilemma, and from here ventures into issues of uniqueness (self/other differentiation) and agency". Bamberg (2011, p.6) then contrasts the construction of identity with "notions of self and sense of self, [which] start from the self/other and agency differentiation and from here can filter into diachronicity of continuity and change". These dilemmatic spaces of continuity and change, sameness and difference, and agency, echo Bakhtin and Holquist's (1981) dialogical approach to interaction. The authors acknowledge the multiplicity of different voices and perspectives, in that an utterance acquires meaning partly by drawing on the voices it indexes. Bakhtin and Holquist (1981, p.293) explain that:

All words have the "taste" of a profession, a genre, a tendency, a party, a particular work, a particular person, a generation, an age group, the day and hour. Each word tastes of the context and contexts in which it has lived its socially charged life; all words and forms are populated by intentions.

In other words, when interacting we use words that have been used by others and these are tinted with the social locations and ideological stances held by others. Bakhtin and Holquist (1981, p. 294) go on to describe that "the word in language is half someone else's. It becomes 'one's own' only when the speaker populates it with [their] own intention, [their] own accent, when [they] appropriate the word adapting it to [their] own semantic and expressive intention". What becomes evident, is that we are in a continuous dialogue between the words we are given, "shot through with [others'] intentions and accents" and our efforts to assign meaning to them (Bakhtin \& Holquist, 1981, p.293). In a similar way, narratives have the potential to 'dialogue' with alternative perspectives and create novel meanings (Brockmeier, 2009).This is achieved through what Bakhtin calls double-voiced discourse; the process through which narrators "represent voices, as well as the process through which voices develop through contact with others" (Wortham, 1998, p.5). Tannen (2007) elaborates on this process by arguing that 
the representation of characters' voices is not a reiteration of a character's utterances but instances of constructed dialogue. Tannen (2007, p.112) contends that "ideas cast as dialogue rather than statements is a discourse strategy for framing information in a way that actively creates involvement". Clark and Gerrig (1990) and Holt (1996) construe constructed dialogue as serving as a "type of demonstration". As Clark and Gerrig (1990, p.764) illustrate demonstrations "depict their referents - what is being demonstrated" and provide interlocutors with direct access to the interaction under discussion so that they are able to assess it for themselves. Thus, voice in narrative becomes a means of positioning characters in the story world and the social world but also a means by which a narrator positions himself with respect to other characters and in relation to these worlds.

\section{Narrative positioning analysis}

This concept of dialogism is reflected in the analytical framework of positioning analysis as applied to the small stories that emerged in this study. Bamberg (1997) and Bamberg and Georgakopoulou (2008, p.385) refined and developed positioning theory in relation to stories told in interaction. Here positioning theory is used to conduct a fine-grained analysis of "separable yet interrelated positioning processes" in small stories. Bamberg and Georgakopoulou (2008) proposed the notion that the narrator can position themselves at three levels:

Level i positioning explores the story, focusing on where the story is set, how the action develops, and how the characters are portrayed. It analyses the kinds of actions the narrators attribute to the main characters and the underlying motives for doing so. It also analyses how the narrator attributes certain characteristics to the protagonist and other characters in the story.

Level ii focuses on the interactive situation. This requires examining how the story is embedded in the surrounding talk, how the story was produced and what the motivation was for doing so. It then looks at how the speakers position themselves in the ongoing interaction and in the storyworld, how they co-construct the story or challenge or endorse other participants' tellings.

Level iii positioning addresses the question of "Who am I?" and is where the participants' position themselves with respect to capital- $D$ discourses and identify a sense of their professional identity. Bamberg (2014) reinforces Gee's (1999) differentiation between capital- $D$ discourses, which are likened to dominant discourses or master narratives, and small- $d$ discourses, which are used to refer to the everyday form of talk. This distinction facilitates an understanding of different ways of analysing identity in discourse (Bamberg et al., 2011). Studies drawing on capital- $D$ discourses perceive identity as being determined by societal macro 
conditions such as communal and institutional contexts, while studies examining small- $d$ discourses make use of the in situ context or the actual choices speakers make "in the form of performed in vivo utterances ... [to understand] how speakers present a sense of who they are" (Bamberg et al., 2011, pp.181-182).

In light of this research, I now go onto discuss the methodology employed in this study and then I explore how interpreters and ALOs perform and construct their professional identities in different narrative activities.

\section{Methodology}

\section{Data collection}

In accordance with The University of Melbourne guidelines for conducting human research, this project was approved by the Humanities and Applied Sciences Human Ethics Sub-Committee, ethics ID number: 1646989.1.

The data for this study comes from a larger corpus of 15 hours of transcribed audio recording from semi-structured interviews conducted with ten interpreters of traditional Aboriginal languages, eight Aboriginal Liaison Officers and one Aboriginal Service Development Worker. The Aboriginal Liaison Officer is responsible for ensuring the delivery of preventative care and culturally responsive services for Aboriginal and Torres Strait Islander patients and their family. They help ensure the hospital meets the particular needs of ATSI patients and their families and increase the cultural sensitivity of healthcare services and providers to Aboriginal health issues. They also assist in building positive relationships with the Victorian Aboriginal community, other service providers, and government departments (https://www.thermh.org.au/health-professionals/clini cal-services/aboriginal-health). The Aboriginal Service Development Worker (ASDW) engages in project work and "works alongside other hospital staff to make certain patients and families receive the care and support that they need" (https://www.thermh.org.au/health-professionals/clinical-services/aboriginalhealth). ALOs and ASDWs are often employed to interpret for Aboriginal and Torres Strait Islander people; however, they are not certified as interpreters by interpreting bodies such as National Accreditation Authority for Translators and Interpreters (NAATI). Interpreters, on the other hand, have NAATI certification. Seven of the Aboriginal Liaison Officers were female and one male; the Aboriginal Service Development worker was female. Three of the interpreters were male and seven were female. They are English speaking or bilingual/multilingual adults, aged 18 and over. All participants were interacting with the author. The data were collected between January 2017 and January 2018 at two Metropolitan hospitals in 
Victoria, one Metropolitan hospital in the Northern Territory, one regional hospital in regional Victoria, and via an interpreting service, in Western Australia.

\section{Data coding and analysis}

Narrative data consists of 25 stories; however, for the purposes of this chapter I selected a purposive sub-sample of 4 stories. These 4 stories are representative of wider patterns within the overall data set illustrating in particular the negotiation and joint construction of professional identities throughout the talk by drawing on different levels of analytic granularity and in doing so they highlight the relationship between small- $d$ and capital- $D$ discourses.

In line with research into discourse analysis, I identified stories as being prefaced by discourse markers such as the common ground discourse marker You know (Maschler \& Schiffrin, 2015); sequential initial So (Bolden, 2009; Jefferson, 1978) Oh-prefaced tellings (Schegloff, 2007) and the discourse markers Okay so, to preface an extended telling (Bolden, 2009). Typical examples of such story prefaces in the dataset include those that:

a. project a forthcoming story: 'So like um, I'll give you, just a quick example, of how that happens.; 'I remember one time,'; 'This is a good example, as well.'

b. make reference to the recency of the reported event: 'So um just recently'.

Discourse markers that signal the telling of a story include:

c. common ground preface You know: 'Um. You know, in most cases, I will say to them,'

d. sequential initial So: 'So um, down in E D um, a couple of years ago,'

e. Oh-prefaced tellings: 'How did .. the doctor understand, in the end?

1Oh so then, so then -'

f. Okay so to preface an extended turn: 'Okay, so we had um a fell - A a a little boy admitted -'

Prefaces were also followed by temporally related clauses; according to Labov and Waletzky (1967) a narrative consists of a sequence of past tense clauses which are sequentially ordered as in: 'I was at footy, and my auntie tol - My auntie rang me up.' However, in line with Georgakopoulou (2015) a large number of stories did not exhibit a linear sequencing of past events; in this dataset these stories were often fragmentary accounts of professional experience or stories that made reference to habitual narratives "which tell of the general course of events over a period of time, with the verb phrases and adverbs marking repetition and routinization" and hypothetical narratives describing events that did not happen (Riessman, 1990, p.1197). 
I use Bamberg and Georgakopoulou's (2008) narrative positioning analysis to examine how the participants positioned themselves at three levels; in level i and ii analysis, I focus on how the characters in the story and the narrators in the ongoing interaction employ indexicality to position themselves and other characters in relation to the social world and by doing so make claims to a certain professional identity (Ochs \& Capps, 2001). I also analyse the way the characters' voices are animated through constructed dialogue in the stories by examining lexical and prosodic cues, which illustrate how narrators index certain positions by aligning characters in their stories with specific social groups (Wortham, 2001).

I use positioning level $i$ and ii to place emphasis on small- $d$ discourses; where "the way the referential world is put together [i.e., at the level of the talked about] points to how tellers index their sense of self in the here and now [at the level of tellership and performance]" (Bamberg et al., 2011, p. 186). Bamberg, De Fina, and Schiffrin (2011, p.186), explain that a focus on content, tellership and performance allows for a "more or less implicit or indirect referencing and orientation to social positions and discourses about and beyond the here and now". Therefore, level i and level ii positioning feed into level iii positioning by highlighting capital- $D$ discourses, "or the general societal contextual conditions" that speakers invoke to make sense of who they are (level iii) (p.181).

These Discourses are made relevant by relating the participants' projected identity to Bamberg's (2011) three dilemmatic spaces. Additionally, through the identification of repeated types of story-lines and patterns or collective representations in other stories in the dataset, I show how positioning processes are linked with "specific types of stories and types of social settings" (De Fina, 2013; Georgakopoulou, 2013, p.92). These are subsequently analysed in relation to wider social processes that are located in the literature.

\section{Results: Narrative positioning analysis}

The narrative positioning analysis brought to the fore capital- $D$ discourses which perceive identity as being determined by societal macro conditions closely tied to health institutional contexts. In the overall dataset, five central capital- $D$ discourses emerged from the narrative positioning analysis including: an 'us and them dichotomy', 'professionalism and accountability', 'differing worldviews and knowledge systems', 'educator and learner' and 'culturally distinct communication patterns. These capital- $D$ discourses highlight the diverse positions that the interpreters and ALOs claim for themselves and other social actors in the stories they narrate. Although none of these capital- $D$ discourses emerge in isolation and all of them overlap and interact with other capital- $D$ discourses showcasing the challenges the interpreters and ALOs face as they fulfil their respective roles 
(Karidakis, 2019), my focus here will be on stories that give prominence to capital- $D$ discourses evoking an 'us and them' dichotomy. This is of particular interest to my analysis as us/them dichotomies seem to be constructed when there is little collaboration between, on the one hand, interpreters and ALOs, and on the other hand, interpreters, health practitioners and health institutions. An us/ them dichotomy thus signals potential difficulties in communication, the provision of culturally safe care to Aboriginal patients and may impact the duty of care of these patients.

\section{Us and them dichotomy}

\section{'You need a Kriol interpreter' story}

The story 'you need a Kriol interpreter' was offered in response to a discussion on the importance of using professional interpreters. Annie, an interpreter of Aboriginal languages in Western Australia including Walmajarri, Fitzroy Valley Kriol and Kimberley Valley Kriol, discusses the difficulties associated with finding an interpreter that speaks a particular traditional Aboriginal language such as Kukatja spoken in Balgo Western Australia. In the ongoing interaction, Annie explains that interpreters mediate between the doctor and patient over the phone. There is a strong preference however, for interpreting in person even though this is not always possible due to lack of funding or institutional support for trained interpreters. This is the impetus underlying Annie's interactional move in Extract 1, from an argumentative sequence to narrating a story that is set in a public hospital where a doctor deems the use of a professional interpreter as unnecessary.

Extract 1. 'You need a Kriol interpreter' story part 1

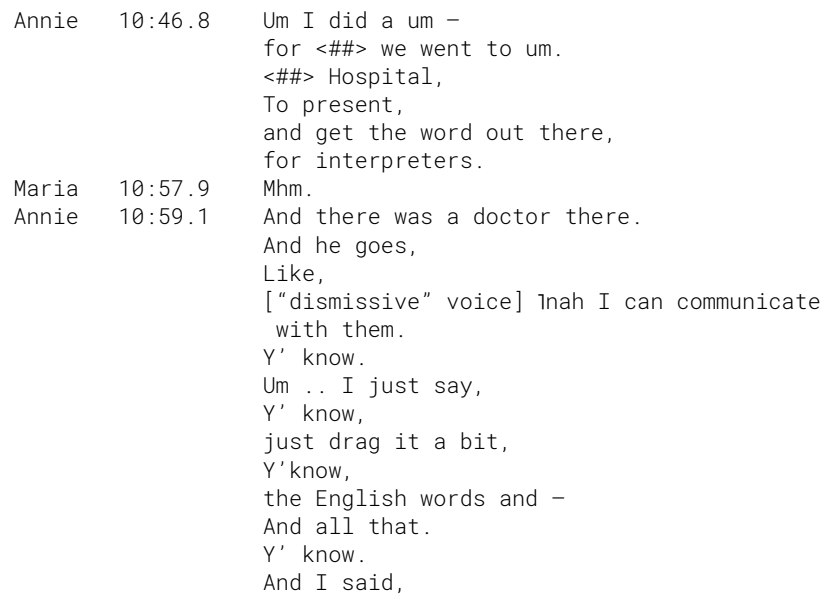




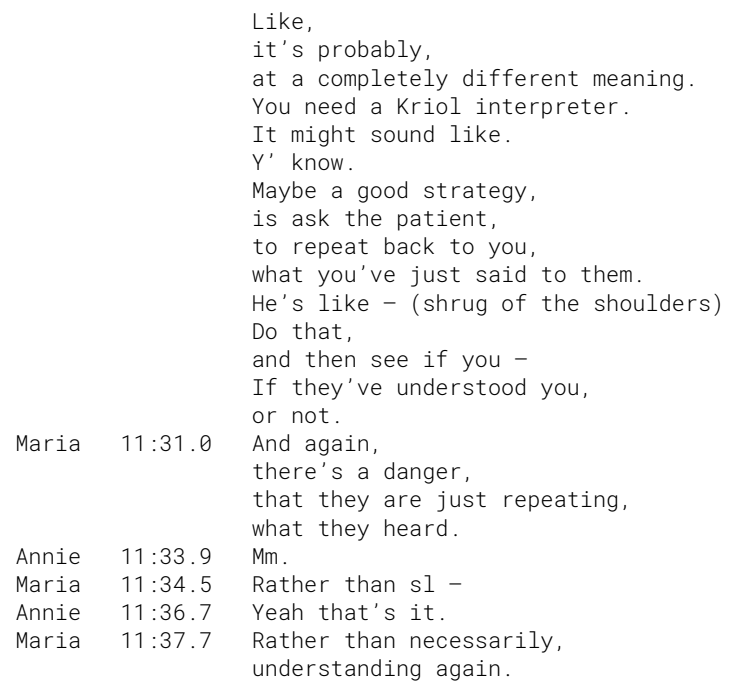

(AA18072017)

Level I positioning - at the level of the story

In line with Labov (2010) who claims that "participants in many narratives include protagonist, antagonist and third party witnesses" (p.548) in the 'you need a Kriol interpreter' story, Annie is both narrator and protagonist, while the doctor is positioned as antagonist. Annie has visited the hospital on a professional level in order to promote the importance of using trained interpreters as her intention is to 'get the word out there, for interpreters' (lines 2-6). The doctor's positioning vis-à-vis the interpreter is dismissive and negatively oriented towards the interpreter and the Aboriginal patients. This is evident in line 11 through his casual rebuff and 'othering' of the Aboriginal patients. It also appears as if the doctor is minimising the work that interpreters do via the lexical choices he makes, 'I just say ... just drag it a bit ... the English words and all that' (lines 14-19). This has the effect of enhancing his own capacities of communication and rendering the process of interpreting redundant. In addition, the doctor underestimates the linguistic barriers that may be present when interpreting for Aboriginal patients. The character Annie, conscious of the doctor's attempt to trivialise the work of the interpreter, draws on her professional positioning to highlight the semantic differences that necessitate the use of a Kriol interpreter (lines 22-23). The doctor's indifference is marked by the lack of a reply. Eventually, Annie appears to submit under the pressure and rather than continue to contest the doctor's refusal to use an interpreter, she offers a strategy for checking Aboriginal patients' understanding (lines 27-30). This is met with a shrug of the shoulders (line 31). This story highlights the challenging of Annie's professional identity as she con- 
tends with the doctor's denigration of her work and brings to the fore the boundaries that are constructed between the two professionals establishing an 'us and them' dichotomy. How this is achieved linguistically in the ongoing interaction is expounded in level II positioning below.

Level II positioning - at the level of the interaction

This story is embedded within talk about the importance of using a professional interpreter particularly when doctors construe the practice as superfluous. Annie's professional identity as interpreter is challenged by the doctor's nonchalant dismissal of what the work of an interpreter entails. In line with McNeill (1992), this dismissive behaviour and attitude is paralinguistically embodied in a shrug of the shoulders. Annie attributes this gesture to the doctor to mark his failure to respond constructively. This embodied narrative event is crucial in constructing and reproducing the perception of a routinised construction of doctors' repeated resistance to the use of interpreters. In this manner, Annie is progressively constructing an 'us and them' dichotomy. This positioning is further reinforced through the use of constructed dialogue (Tannen, 2007). There is only one instance where there is a shift in voice quality in the story and this is in lines 11-19. Here the doctor is animated in a dismissive voice and the quality of that voice creates the persona that Annie is constructing for him; that of an uncooperative and perhaps ill-informed medical professional. Through the animation of the dialogue with a highly marked voice quality, Annie constructs a tension between what appear to be lifelike characters and as a result the audience becomes involved by actively aligning with the 'us and them' positioning. This is evidenced by the interviewer's contribution to the ongoing interaction once Annie has stepped out of the story world. The interviewer questions the use of repetition as a knowledge checking strategy and draws on an earlier discussion on gratuitous concurrence, what Eades (2016, p. 476) refers to as "the act of saying yes to a question, regardless of whether the speaker agrees with the proposition being questioned, or even understands it". Annie uses the term when discussing the pitfalls of addressing yes/no questions to Aboriginal patients. The interviewer's interjection here highlights the inherent dangers of relying on repetition of an utterance as there is no guarantee of understanding.

This discussion on gratuitous concurrence prompts Annie to revisit her story. This extract narrates hypothetical events that are employed as a strategy for evaluation of the original story presented above in Extract 1. Annie questions her handling of the doctor's positioning of herself, the interpreter, as redundant and offers the hypothetical story to evaluate what did not happen in the story world, in Extract 1. The complete story is presented in Extract 2 below. 
Extract 2. 'You need a Kriol interpreter' story part 2

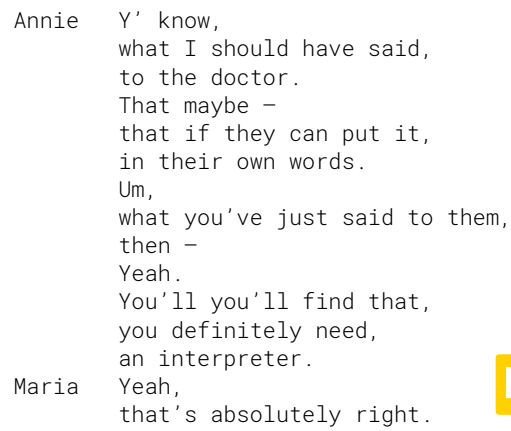

(AA18072017)

Linguistically, Anne's use of the discourse marker 'you know' (line 46) indicates the connection between the irrealis in Extract 2 and the story world in Extract 1, thus relating informational units in the discourse to each other (Schiffrin, 1987). Annie is setting up the irrealis to directly evaluate her actions in the story world; and it appears as if these are deemed as inadequate given that Annie's use of deontic modality in 'what I should have said to the doctor' (line 47-48) expresses an unfulfilled obligation or an action that was neglected (Palmer, 2001; Van Der Auwera \& Plungian, 1998). She proceeds to use 'if' to introduce the conditions under which the subsequent hypothetical event takes place (lines 49-58). Namely, hypothetically requesting that Aboriginal patients rephrase a doctor's utterances. However, she concludes that the Aboriginal patient would not be able to do so. In effect, Annie is returning to her initial premise and positioning; that it is imperative that doctors use professional interpreters and the emphatic stress on the adverb 'definitely' reinforces this positioning (lines 57-58). The interviewer's overt agreement in 'Yeah, that's absolutely right' (lines 59-60) shows complete alignment with Annie's move to reject the strategies that she had proposed to the doctor. It appears that Annie is reporting that she was indirectly placating the resistant doctor via the provision of strategies the doctor could employ while consulting with Aboriginal patients. In hindsight, these strategies are considered ineffectual and Annie reclaims her initial positioning asserting her identity as a professional interpreter.

I now turn to level 3 positioning to reflect how Annie navigates Bamberg's (2011) three dilemmatic spaces to construct a professional identity and I then illustrate how similar patterns emerge in other stories and across the literature. 


\section{Level III positioning - addressing the question "Who am I?"}

Annie's stories portray the challenges inherent in interpreter mediated interactions when doctors display resistance towards incorporating professional interpreters during their communicative encounters with Aboriginal patients. This may strain relations between these two professional groups and widen the gulf between them, thereby constructing a Discourse surrounding an us and them dichotomy. Looking back to Extract 1, Annie's professional identity is challenged by erroneous assumptions that undermine the work of interpreters. As Level 3 positioning sets out to answer the question who am I? "above and beyond the current storytelling situation" (De Fina \& Georgakopoulou, 2012, p.181), we can see how Annie navigates her identity through Bamberg's (2011) three dilemmatic spaces. With respect to the first dilemmatic space, "constancy and change", Annie shows how her professional identity evolves over time. On the onset, she foregrounds her professional positioning as a Kriol interpreter through her resolve to promote the work of accredited interpreters in health institutional settings. She perceives the doctor as an antagonist and only orients to his perspective when her professional identity is undermined by the doctor's trivialising the work the interpreters do. Upon reflection, in Extract 2, Annie questions her response to the doctor's dismissive positioning and reclaims her identity as a professional Kriol interpreter. In terms of the second dilemmatic space, the navigation of "sameness and difference with respect to self and others", Annie emerges as same as other accredited interpreters through the recognition of their utility and indispensability in doctor-patient interactions with Aboriginal patients whose first language is not English. She emerges as different from the mainstream doctor via her negative positioning and animated portrayal of the doctor's resistance to incorporate interpreters in their communicative encounters with Aboriginal patients. Finally, in the third dilemmatic space, "the management of agency of the self in the world", it seems that power differentials exist between the doctor and interpreter, as the doctor exerts his power by drawing on the status proffered to him by the institution that legitimises or acquiesces to the use of unofficial interpreting. However, Annie is able to exert her influence on the social structures that challenge the utility of the interpreter and exhibits the agency to make decisions and express them in behaviour as she condemns the doctor and reclaims her identity as a professional in her field.

Discourses and ideologies surrounding an 'us and them dichotomy' are invoked in the following stories, which exhibit similar patterns as interpreters Gary and Francesca often face institutional resistance as they undertake to advocate or interpret for Aboriginal patients. 


\section{'Unofficial Kriol interpreting' story}

Extract 3, the 'unofficial Kriol interpreting' story was offered in response to a discussion on the misconception about Aboriginal people's fluency in English. Gary, a Kriol interpreter, narrates a story about Justin, who is an Aboriginal patient, and a head doctor, who asks Justin to give consent about his impending transfer to a metropolitan hospital. However, the patient has received no information concerning what has precipitated such a move. Gary, who is visiting Justin, as a friend at the time, is called to act as an interpreter on an informal basis, something which defies hospital policy. In the full version of the story, Gary has narrated how he came to visit his Aboriginal friend who is also a Kriol speaker in hospital. The following sequence follows the head doctor's entry into the ward.

\section{Extract 3. 'Unofficial Kriol interpreting' story}

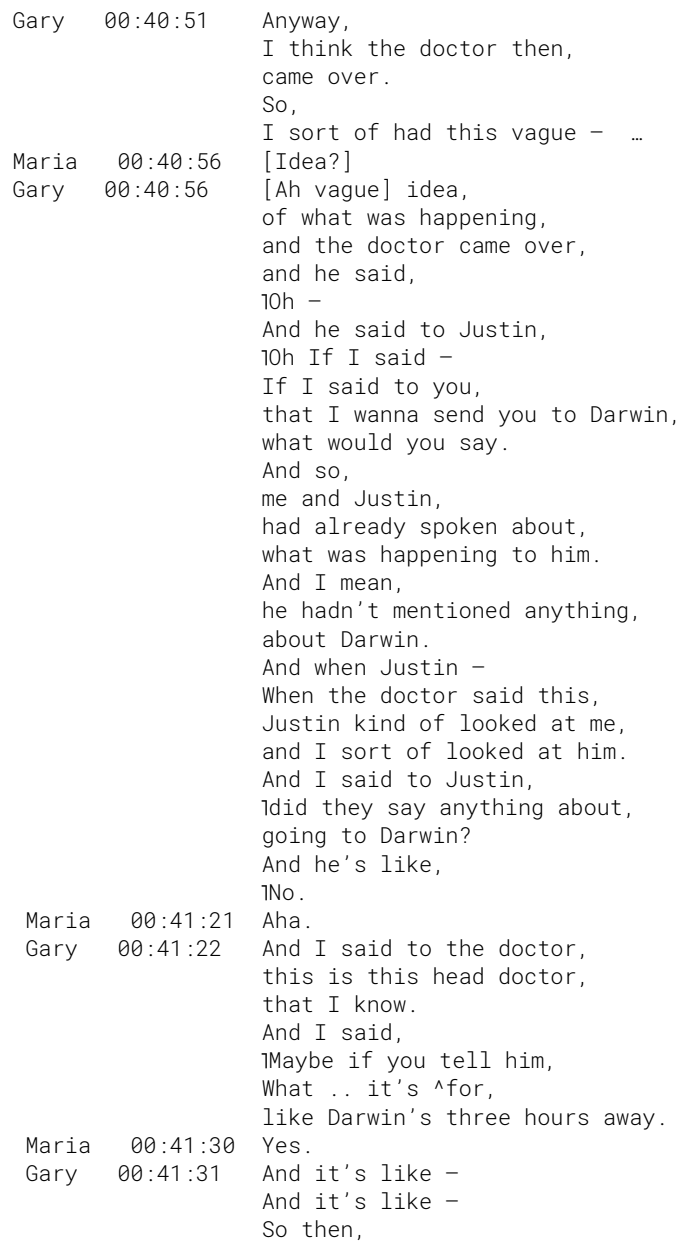


it's even further,

from this remote community, as well.

And I said,

10h well,

maybe if you tell him, what it's about,

the,

$\mathrm{He}-$

he can make a decision, about if he would go,

or not.

And the doctor was like. 10h No.

well, I was just asking, because some people,

just say they don't wanna go, to Darwin.

And I was like,

Tyeah?

So yes.

But he needs to know,

what it's for,

and he can make a decision.

I'm like,

and so,

this like straight away,

I had my backup,

because I'm like,

you kind of asking someone,

if -

To me,

it sounds like,

you're asking for consent for something, without ^any information about,

what it's for?

Maria 00:42:02 Wow, yeah.

Gary 00:42:03 So,

I was just like

what is going on in here?

And Justin -

And Justin said,

1No,

they haven't mentioned anything about,

like going to Darwin.

So,

he didn't know,

what was going on either.

And I was like..

You need to tell him,

what it's for.

He's like,

10kay,

we' 11 look.

I'll come back and -

He said,

I'll come back and explain,

a little bit more.

And Gary.

if you can interpret,

then that will be great

So,

he went off.

And I was getting real -

That kind of really,

knocked me for six that. 


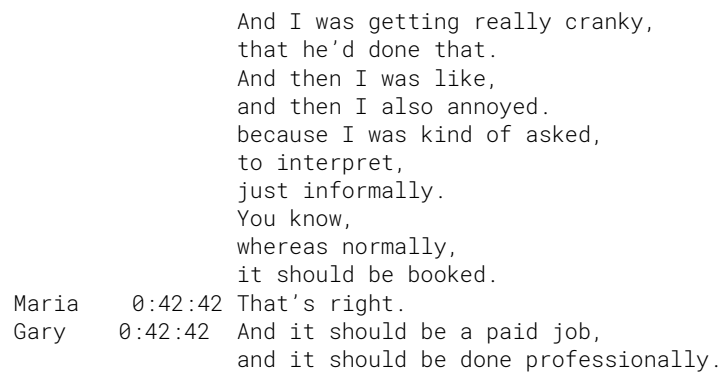

(GG12062017)

Gary's story mirrors Annie's story in Extract 1, not in terms of challenging the utility of his interpreting for Aboriginal patients, but in terms of undermining his status as a professional interpreter. There is an implicit understanding that an interpreter should be commissioned using formal procedures and not sanctioned in an ad hoc manner. There is also the added issue of offering one's services free of charge. Another issue that Gary raises is the transfer of the patient to Darwin without obtaining informed consent from the patient. This is when Gary's alignment with the patient is evidenced as he questions the doctor's handling of the patient's imminent transfer to a metropolitan hospital without having informed the patient about what has necessitated such a move (lines 48-56). The doctor's dismissal of the interpreter's concern and his underplaying the patient's right to information about his condition, finds expression in constructed dialogue in lines $57-68$.

The doctor is positioned as minimising his initial request for a transfer through the mitigating phrase 'I was just asking' (line 59). Coupled with this, the doctor's use of the generic 'some people' may potentially point to the doctor's engaging in 'othering' of Aboriginal patients in general, thus reinforcing the 'us and them' dichotomy. This is something that Gary picks up on and immediately contests with 'yeah?', which is uttered as an appeal. Gary then proceeds to specify the doctor's utterance by referring to Justin using a third person pronoun, stating that 'he needs to know, what it's for, and he can make a decision'.

$\bar{W}$ hen Gary is called to interpret informally, he becomes thoroughly perturbed, and this is expressed through his choice of specific linguistic forms such as the idiomatic cricketing phrase, 'knocked me for six', and inclusion of evaluative intensifiers and adjectives in 'really cranky' and, 'annoyed' (lines 110-111, 114). The tension created by this unlicensed request, constructs an 'us and them dichotomy' as Gary's professionality as an interpreter is not acknowledged when he is called upon to interpret unofficially. 


\section{'We'll ring you when we need you' story}

The following story, 'we'll ring you when we need you' story bears resemblance to Annie's stories (Extracts 1 and 2). The common theme pervading these stories is institutional resistance to using professional interpreters. The story that ensues commences at line 9:

\section{Extract 4. 'We'll ring you when we need you' story}

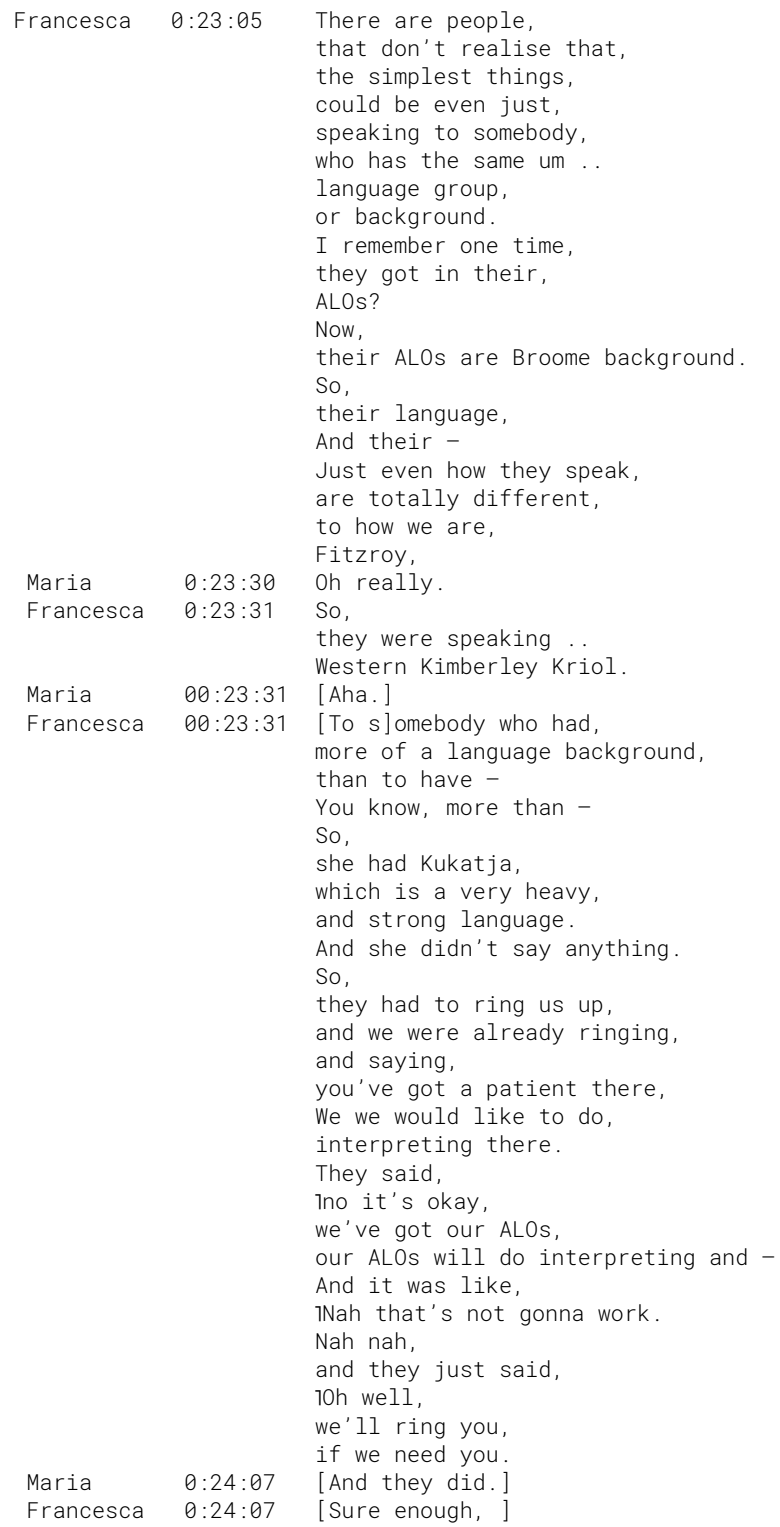




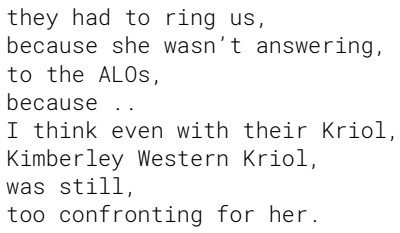

$(\mathrm{FF} 19072017)$

In the ongoing interaction Francesca, an interpreter of Aboriginal languages including Kriol and Walmajarri has noted that differences exist between even geographically proximate language groups and that geographical proximity does not equate to mutual intelligibility. In this story an 'us and them' dichotomy is constructed as interpreters are pitched in direct opposition to ALOs when offers to assist in interpreting for an Aboriginal patient are refused. Linguistically, this is achieved through the repetition of first-person plural pronoun 'our' in 'We've got our ALOs' and 'Our ALOs will do interpreting' (lines 44-45) and the repetition of near-synonymous phrases such as: 'And she didn't say anything' (line 34) and 'because she wasn't answering' (line 56). It also appears that the hospital staff deem the use of an interpreter unnecessary despite being warned that the use of Western Kimberley Kriol speaking ALOs will not suffice with 'Nah that's not gonna work'. In addition, the hospital staff's reluctance to commission the help of an interpreter is prefaced with the discourse markers '1Oh well', in ' 10 h well, we'll ring you, if we need you' and as discussed by Heritage (2015, p.90), turn initial discourse markers such as 'oh well' may index a stance of reluctance or be "a harbinger of rejecting”.

This analysis has shown that medical interpreters and ALOs report that they may have their professional identity questioned, undermined or dismissed. They express their concerns over health practitioners' reluctance to use interpreters and this is a trend that is widely acknowledged. Instead of commissioning medical interpreters as a first resort, they may be commissioned only when the communicative encounter breaks down. Ralph et al., (2017, p.9) also discuss the "preferential use of unofficial interpreters (family members) for convenience". Such resistance towards a joint cooperation between health practitioners and professional interpreters may construct Discourses related to an 'us and them dichotomy' which positions health practitioners in opposition to interpreters or ALOs. This positioning in effect impacts the duty-of-care of Aboriginal patients. As Ralph et al. (2017, p.10) assert "inadequate uptake of interpreters is emerging as a leading knowledge practice gap nationally and internationally".

Similar findings have been reiterated by Doane and Varcoe (2005) who point out that institutional resistance to the use of interpreters creates tension and is not conducive to the provision of culturally safe care to Aboriginal patients. Doane 
and Varcoe (2005, p.304) assert that attending to cultural differences "cannot be overlooked, discounted, erased, or trivialized - they must be taken seriously". However, when conceptualisation of culture is narrow in scope there is a tendency to construe culture as static or fixed and as a consequence particular behaviours, values and beliefs are inherent to particular groups (Doane \& Varcoe, 2005; Kirkham et al., 2002). This attribution of certain cultural traits to different ethnocultural groups singles out those traits that are perceived as different from the assumed dominant norm. Culturalist discourses help shape mainstream and Aboriginal assumed identities by constructing a binary between Other cultures and Western cultures (Narayan, 2000). Ahmad (1993) explicates that by 'defining the Other (usually as inferior) one implicitly defines oneself against that definition (usually as normal or superior).' With reference to culturalist discourse about Aboriginal people, McConaghy (2000, p.83) contends:

... frequently these images and stereotypes limit and contain Indigenous people and prevent them from attaining material and symbolic gains. In a real sense, these images objectify and de-humanise Indigenous people ... It is this notion of culture which allows Indigenous people to be othered in colonialism.

Health practitioners may draw upon "discourses that construct people in ways that reflect popularized negative stereotypes" (Browne \& Varcoe, 2006, p.161). As we have seen, such othering of Aboriginal patients finds expression in several small stories through the use of generic references to Aboriginal patients as in the 'unofficial Kriol interpreting' story where doctors may refer to them generically as 'some people' and hence make far-reaching generalisations about Aboriginal patients. Therefore, as Downing and Kowal (2011, p.8) note "by creating a false dichotomy of cultures - 'us' and 'them' - there is a risk of generating and perpetuating power imbalances in health service provision in which certain cultural beliefs of mores are privileged over others".

\section{Discussion and conclusion}

Storytelling is one of the discursive means by which the "deep cultural and historical knowledge that make up the social and cultural identity of Aboriginal people" is imparted (Ober, 2017, p. 8). It is a means of validating an Aboriginal self and as Ober (2017, p.8) explains storytelling or yarning is deeply rooted in "the processes and structure of Aboriginal society". Collins and Cooper $(2005$, p.1) also suggest that "storytelling becomes a vehicle for discovering who we are, for making sense of our world, for enhancing our learning/teaching, and for plain old fun". Through the exchange of stories, the interpreters and ALOs in this study con- 
tribute their understandings of the complexities of interpreting in medical settings that Aboriginal and non-Aboriginal patients are likely to experience and in doing so demonstrate the construction of not a single identity but multiple shifting identities. Therefore, the interpreters' and ALOs' identity emerges not as a static attribute of individuals or as associated with comparatively fixed social categories such as gender or race, but as Bucholtz and Hall (2005) assert identity is framed as a dynamic, hybrid, fragmented construct that is established in relation to other social actors or identity positions. For the interpreters and ALOs in this study, the telling of a story seems to be a relational practice; it becomes a dialogue between the teller and listener, who are actively involved in the telling. This active involvement manifests in the manner in which the participants step out of both their professional roles as interpreters and ALOs, and their situated roles as interviewees and adopt the role of narrators as they shift from argumentative sequences into story-mode. Therefore, these shifts into storytelling mode are not haphazard. They are as Bamberg (2016, p. 1292, emphasis in the original) notes, offered intentionally and "are embedded in previous and subsequent turns, that is interactive befores and afters". At times, the researcher also shifts roles from interviewer to co-participant, as she relates to the story in various ways: questioning, predicting and imagining and in effect at times contributing to the co-construction of the story. Approaching stories from a small story, practice-based approach, sees language "performing specific actions in specific environments and as being part of social practices, shaping and being shaped by them" (Georgakopoulou, 2015, p. 257). This practice-based approach closely relates to the way in which stories are perceived in Aboriginal communities in Australia. The participants in the study share a cultural understanding of the role that stories plays in their professional lives and this is in line with Bamberg (2016, p.1292) who explains that this shared cultural understanding is "due to continuous bodily and verbal practicing of their social interactions in mundane and everyday activities".

The findings underscore the strengths of narrative positioning analysis as it illustrates the "inextricability of the two worlds involved in any storytelling: that of the told world (level i) and of the telling world, i.e. the here-and-now of storytelling (level ii)" (Georgakopoulou, 2013, p.91). In this way, the interpreters and ALOs as narrators position themselves in the story world and the here-andnow of the interaction and at the same time maximise on opportunities for selfpresentation "afforded by their deictic separation/separability on the one hand and, on the other hand, by the possibilities for the teller to stress and maximize their interconnections" (Georgakopoulou, 2013, p. 91). The framework also shows how locally produced and enacted identities are linked to wider capital- $D$ discourses and macro social processes (level iii). 
Bamberg's model thus presents an analytical tool-kit for "linking local telling choices to larger identities" (De Fina \& Georgakopoulou, 2012, p.164). However, it has also been critiqued with respect to some of the assumptions underlying positioning analysis. Hall (2004, p. 355) argues that positioning at level 3 "pursues inferences about dominant or master narratives that are not demonstrably relevant for participants in the ongoing conversation". This echoes Conversation Analysis researchers who argue that dominant discourse or capital- $D$ discourses should explicitly be oriented to by the participants in an interaction to be considered relevant (Heritage \& Clayman, 2010). Recent work, however, has attempted to address this disparity in methodological approaches by suggesting a middle ground between CA approaches that "centre exclusively on participant orientations at a local level and approaches that regard identity as basically determined by macro social processes" (De Fina, 2013, p. 40). In an attempt to mitigate these limitations, firstly, I incorporated Bamberg's (2011) dilemmatic spaces into positioning level iii and show how each dilemmatic space seeks to provide an answer to the question "who am I?" and therefore presents some challenge for identity work. Secondly, by locating repeated types of story-lines or what Georgakopoulou (2013) refers to as 'iterativity' and looking for "patterns" (De Fina, 2013) what becomes apparent was that the interpreters and ALOs were invoking capital- $D$ discourses that were constructed in relationships of complicity with other capital- $D$ discourses, particularly when the positioning of the storytellers aligned across the data set. This shed light on the multiple, shifting, professional positions and identities that the interpreters and ALOs claim for themselves and other social actors in the stories they narrated (Karidakis, 2019).

We have seen that the interpreters and ALOs bring their previous professional experiences into discourses surrounding healthcare interpreting. In effect, raising awareness of the multiple, shifting positions interpreters and ALOs adopt in the stories they tell, may help these professionals become better aware of the assumptions they may have of themselves as interpreters, and better understand how they ascribe positions to other social actors such as doctors and Aboriginal patients. It is also increasingly necessary for health institutions and policy makers to acknowledge the multi-faceted role of the medical interpreter. One means of achieving this is by engaging in discussions around positioning in interpreter education programs as this has the potential to help interpreter candidates to critically analyse and challenge the positions, storylines and associated capital- $D$ discourses interpreters invoke to converse about the work they do or to showcase their professional identity. Medical health practitioners may also draw on these findings to better understand storylines that support wider capital- $D$ discourses such as those that invoke an 'us and them dichotomy'. Moreover, raising awareness of these multiple positions and interrelated capital- $D$ discourses may also 
enhance health practitioners and interpreter collaboration as the former come to better understand the multifaceted role that interpreters and ALOs serve.

Although, the use of narrative positioning in the analysis of interviews is unique to the field of interpreting studies, there are limitations to relying on interview data as opposed to actual naturalistic interpreting sessions. Hammersley and Gomm (2008, p.100) acknowledges this limitation with:

what people say in an interview will indeed be shaped, to some degree, by the questions they are asked; the conventions about what can be spoken about; ... by what ... they think the interviewer wants; by what they believe he/she would approve or disapprove of.

A further limitation is what Labov (1972) refers to as the observer's paradox where in this study the participants' contributions in the interview setting were limited to what they were prepared to disclose about their perceptions of interpretermediated interactions. Therefore, the perspectives and positioning of the interpreters and ALOs might be subjective and have the potential to change over time according to circumstance. It is also the case that when placed into a research setting the interpreters and ALOs were likely to offer ethically appropriate or training-induced contributions. In addition to this, the participants were often keen to offer 'good examples' so as to ensure that I collect suitable data. My role as an interviewer and my encouraging and supportive attitude may also have precipitated such responses. Despite these limitations, the use of small story research and narrative positioning analysis has given etic insights into aspects of the professional lives of the interpreters and ALOs in this study.

Though beyond the scope of this study, future research could be enriched by including a linguistic ethnographic perspective. This would permit an analysis of small stories over time coupled with insights gained via systematic ethnographic observations recorded in field notes. These combined approaches would enable the researcher to trace the progression of the participants' projected identities and thus provide additional insights into the Discourses the participants are invoking in order to make sense of their professional identity. A linguistic ethnographic perspective would also situate the research in its direct socio-cultural context and a more holistic perspective could be gained if potential stories offered by health practitioners and Aboriginal patients is included in the study. 


\section{References}

The Royal Melbourne Hospital. (n.d.). Aboriginal health. Retrieved April 27, 2020, from https://www.thermh.org.au/health-professionals/clinical-services/aboriginal-health

Ahmad, W.I.U. (1993). "Race" and health in contemporary Britain. Buckingham/ Philadelphia: Open University Press.

Antaki, C., \& Widdicombe, S. (Eds.). (1998). Identities in talk. London: Thousand Oaks; California: SAGE Publications.

Bakhtin, M. M., \& Holquist, M. (1981). The dialogic imagination: four essays. Austin: University of Texas Press.

Bamberg, M. (1997). Positioning Between Structure and Performance. Journal of Narrative and Life History, 7(1-4), 335-342. https://doi.org/10.1075/jnlh.7.42pos

Bamberg, M. (2006). Stories: Big or small: Why do we care? Narrative Inquiry, 16(1), 139-147. https://doi.org/10.1075/ni.16.1.18bam

Bamberg, M. (2011). Who am I? Narration and its contribution to self and identity. Theory \& Psychology, 21(1), 3-24. https://doi.org/10.1177/0959354309355852

Bamberg, M. (2014). Narrative Practices Versus Capital-D Discourses: Ways of Investigating Family: Native practices. Journal of Family Theory \& Review, 6(1), 132-136. https://doi.org/10.1111/jttr.12033

Bamberg, M. (2016). Narrative. In The International Encyclopedia of Communication Theory and Philosophy (eds K. B. Jensen, E.W. Rothenbuhler, J.D. Pooley and R. T. Craig). https://doi.org/10.1002/9781118766804.wbiect175

Bamberg, M. (2016). Narrative Inquiry. In The International Encyclopedia of Communication Theory and Philosophy (eds K. B. Jensen, E.W. Rothenbuhler, J.D. Pooley and R. T. Craig). https://doi.org/10.1002/9781118766804.wbiect239

Bamberg, M., De Fina, A., \& Schiffrin, D. (2011). Discourse and Identity Construction. In S. J. Schwartz, K. Luyckx \& V.L. Vignoles (Eds.), Handbook of Identity Theory and Research (pp. 177-199). New York: Springer New York. https://doi.org/10.1007/978-1-4419-7988-9_8

Bamberg, M., \& Georgakopoulou, A. (2008). Small stories as a new perspective in narrative and identity analysis. Text \& Talk, 28(3), 377-396. https://doi.org/10.1515/TEXT.2008.018

Bolden, G. B. (2009). Implementing incipient actions: The discourse marker 'so' in English conversation. Journal of Pragmatics, 41(5), 974-998. https://doi.org/10.1016/j.pragma.2008.10.004

Brockmeier, J. (2009). Reaching for Meaning: Human Agency and the Narrative Imagination. Theory \& Psychology, 19(2), 213-233. https://doi.org/10.1177/0959354309103540

Browne, J., D'Amice, E., Thorpe, S., \& Mitchell, C. (2014). Feltman: evaluating the acceptability of a diabetes education toel for Aboriginal health workers. Australian Journal of Primary Health, 20(4), 319 -322. https://doi.org/10.1071/PY14040

Bucholtz, M., \& Hall, K. (2005). Identity and interaction: a sociocultural linguistic approach. Discourse Studies, 7(4-5), 585-614. https://doi.org/10.1177/1461445605054407

Clark, H.H., \& Gerrig, R. J. (1990). Quotations as Demonstrations. Language, 66(4), 764. https://doi.org/10.2307/414729

Collins, R., \& Cooper, P.J. (2005). The power of story: teaching through storytelling. Illinois: Waveland Press Inc. 
De Fina, A. (2011). Discourse and Identity. In T. Van Dijk (Ed.), Discourse Studies: A Multidisciplinary Introduction (pp. 263-282). London: SAGE Publications Ltd. https://doi.org/10.4135/9781446289068.n13

De Fina, A. (2013). Positioning level 3: Connecting local identity displays to macro social processes. Narrative Inquiry, 23(1), 40-61. https://doi.org/10.1075/ni.23.1.03de

De Fina, A., \& Georgakopoulou, A. (2012). Analyzing narrative: discourse and sociolinguistic perspectives. Cambridge/New York: Cambridge University Press.

De Fina, A., Schiffrin, D., \& Bamberg, M. (Eds.). (2006). Discourse and Identity (Studies in Interactional Sociolinguistics). Cambridge: Cambridge University Press. https://doi.org/10.1017/CBO9780511584459

Doane, G.H., \& Varcoe, C. (2005). Family nursing as relational inquiry: developing healthpromoting practice. Philadelphia: Lippincott Williams \& Wilkins.

Downing, R., \& Kowal, E. (2011). A postcolonial analysis of Indigenous cultural awareness training for health workers. Health Sociology Review, 20(1), 5-15. https://doi.org/10.5172/hesr.2011.20.1.5

Du Bois, J.W. (2007). The Stance Triangle. In R. Englebretson (Ed.), Stancetaking in Discourse: Subjectivity, Evaluation, Interaction (pp. 139-182). Amsterdam: John Benjamins Publishing Company. https://doi.org/10.1075/pbns.164.07du

Eades, D. (2016). Judicial understandings of Aboriginality and language use. Judicial Review: Selected Conference Papers: Journal of the Judicial Commission of New South Wales, 12(4), 471-490.

Freeman, M. (2007). Life "on holiday"?: In defense of big stories. In M. Bamberg (Ed.), Narrative-State of the Art (pp. 156-164). Amsterdam: Benjamins.

Gee, J.P. (1999). An introduction to discourse analysis: theory and method. London/ New York: Routledge.

Georgakopoulou, A. (2006). Thinking big with small stories in narrative and identity analysis. Narrative Inquiry, 16(1), 122-130. https://doi.org/10.1075/ni.16.1.16geo

Georgakopoulou, A. (2007). Small stories, interaction and identities. Amsterdam/ Philadelphia: John Benjamins. https://doi.org/10.1075/sin.8

Georgakopoulou, A. (2013). Building iterativity into positioning analysis: A practice-based approach to small stories and self. Narrative Inquiry. 23(1), 89-110. https://doi.org/10.1075/ni.23.1.05geo

Georgakopoulou, A. (2015). Small Stories Research: Methods - Analysis - Outreach. In A. De Fina \& A. Georgakopoulou (Eds.), The Handbook of Narrative Analysis (pp. 255-271). Hoboken, NJ: John Wiley \& Sons, Inc. https://doi.org/10.1002/9781118458204.ch13 Georgakopoulou, A. (2016). From Narrating the Self to Posting Self(ies): A Small Stories Approach to Selfies. Open Linguistics, 2(1), 300-317. https://doi.org/10.1515/opli-2016-0014

Georgakopoulou, A. (2017). Narrative/Life of the Moment: From Telling a Story to Taking a Narrative Stance. In B. Schiff, A.E. McKim \& S. Patron (Eds.), Life and narrative: the risks and responsibilities of storying experience (pp. 29-54). New York: Oxford University Press. https://doi.org/10.1093/acprof:oso/9780190256654.003.0003

Goodwin, C. (1986). Audience diversity, participation and interpretation. Text Interdisciplinary Journal for the Study of Discourse, 6(3), 283-316. https://doi.org/10.1515/text.1.1986.6.3.283

Hall, R. (2004). Attaching Self and Others to Social Categories as an Interactional and Historical Achievement. Human Development, 47(6), 354-360. https://doi.org/10.1159/000081037 
Hammersley, M., \& Gomm, R. (2008). Assessing the radical critiques of interviews. In M. Hammersley (Ed.), Questioning Qualitative Inquiry: Critical Essays (pp. 89-100). London: SAGE. https://doi.org/10.4135/9780857024565.d7

Heritage, J. (2015). Well-prefaced turns in English conversation: A conversation analytic perspective. Journal of Pragmatics 88, 88-104. https://doi.org/10.1016/j.pragma.2015.08.008

Heritage, J., \& Clayman, S. (2010). Talk in action: interactions, identities, and institutions. Chichester Malden: Wiley-Blackwell. https://doi.org/10.1002/9781444318135

Holt, E. (1996). Reporting on Talk: The Use of Direct Reported Speech in Conversation. Research on Language \& Social Interaction, 29(3), 219-245. https://doi.org/10.1207/s15327973rlsi2903_2

Jefferson, G. (1978). Sequential aspects of storytelling in conversation. In J. Schenkein (Ed.), Studies in the organization of conversational interaction (pp. 219-248). New York: Academic Press. https://doi.org/10.1016/B978-0-12-623550-0.50016-1

Johnstone, B. (2008). Discourse analysis. Malden, MA: Blackwell.

Karidakis, M. (2019). Communicating in medical settings: strategies \& challenges for effective cross-cultural interpreting (Doctoral dissertation, The University of Melbourne, Melbourne, Australia). Retrieved from http://hdl.handle.net/11343/220710

Kirkham, S. R., Smye, V., Tang, S., Anderson, J., Blue, C., Browne, A., Coles, R., Dyck, I., Henderson, A., Lynam, M. J., Perry, J., Semeniuk, P., \& Shapera, L. (2002). Rethinking cultural safety while waiting to do fieldwork: Methodological implications for nursing research. Research in Nursing \& Health, 25(3), 222-232. https://doi.org/10.1002/nur.10033

Labov, W. (1972). Sociolinguistic patterns. Philadelphia: University of Pennsylvania Press.

Labov, W. (2010). Narratives of Personal Experience. In P. Hogan (Ed.), Cambridge Encyclopedia of the Language Sciences. Cambridge: Cambridge University Press.

Labov, W., \& Waletzky, J. (1967). Narrative analysis: oral versions of personal experience. Journal of Narrative and Life History, 7(1-4), 3-38.

Maschler, Y., \& Schiffrin, D. (2015). Discourse Markers Language, Meaning, and Context. In D. Tannen, H.E. Hamilton \& D. Schiffrin (Eds.), The Handbook of Discourse Analysis: Tannen/Discourse (pp. 189-221). Hoboken, NJ, USA: John Wiley \& Sons, Inc. https://doi.org/10.1002/9781118584194

McConaghy, C. (2000). Rethinking indigenous education: culturalism, colonialism and the politics of knowing. Flaxton, Qld: Post Pressed.

McNeill, D. (1992). Hand and mind: what gestures reveal about thought. Chicago: University of Chicago Press.

Narayan, U. (2000). Essence of culture and sense of history: A feminist critique of cultural essentialism. In U. Narayan \& S. G. Harding (Eds.), Decentering the center: philosophy for a multicultural, postcolonial, and feminist world (pp. 80-100). Bloomington, IN: Indiana University Press.

Ober, R. (2017). Kapati Time: Storytelling as a Data Collection Method in Indigenous Research. Learning Communities: International Journal of Learning in Social Contexts, 22, 8-15. https://doi.org/10.18793/LCJ2017.22.02

Ochs, E., \& Capps, L. (2001). Living narrative: creating lives in everyday storytelling. Cambridge: Harvard University Press.

Palmer, F. R. (2001). Mood and modality (2nd ed). Cambridge, UK; New York: Cambridge University Press. https://doi.org/10.1017/CBO9781139167178 
Ralph, A.P., Lowell, A., Murphy, J., Dias, T., Butler, D., Spain, B., Hughes, J.T., Campbell, L., Bauert, B., Salter, C., Tune, K., \& Cass, A. (2017). Low uptake of Aboriginal interpreters in healthcare: exploration of current use in Australia's Northern Territory. BMC Health Services Research, 17(1). https://doi.org/10.1186/s12913-017-2689-y

Riessman, C.K. (1990). Strategic uses of narrative in the presentation of self and illness: a research note. Social Science \& Medicine, 30(11), 1195-1200. https://doi.org/10.1016/0277-9536(90)90259-U

Schegloff, E.A. (2007). Sequence organization in interaction: a primer in conversation analysis. Cambridge/New York: Cambridge University Press. https://doi.org/10.1017/CBO9780511791208

Schiffrin, D. (1987). Discourse markers. Cambridge: Cambridge University Press. https://doi.org/10.1017/CBO9780511611841

Silverstein, M. (1980). Shifters, Linguistic Categories, and Cultural Description. In K.H. Basso \& H.A. Selby (Eds.), Meaning in anthropology (pp. 11-55). Albuquerque: University of New Mexico Press.

Tannen, D. (2007). Talking voices: repetition, dialogue, and imagery in conversational discourse. Cambridge: Cambridge University Press. https://doi.org/10.1017/CBO9780511618987

Van Der Auwera, J., \& Plungian, V.A. (1998). Modality's semantic map. Linguistic Typology, 2(1). https://doi.org/10.1515/lity.1998.2.1.79

Van Dijk, T. (2011). Discourse Studies: A Multidisciplinary Introduction. London: SAGE Publications Ltd. https://doi.org/10.4135/9781446289068

Varcoe, C., \& Browne, A. (2006). Critical cultural perspectives and health care involving Aboriginal peoples. Contemporary Nurse: A Journal for the Australian Nursing Profession, 2,155 .

Watson, C. (2007). Small Stories, Positioning Analysis, and the Doing of Professional Identities in Learning to Teach. Narrative Inquiry, $17(2), 371-389$. https://doi.org/10.1075/ni.17.2.11wat

Wortham, S.E. F. (1998). Knowledge and Action in Classroom Practice: A Dialogic Approach. GSE Publications, 1-11.

Wortham, S.E.F. (2001). Narratives in action: a strategy for research and analysis. New York: Teachers College Press.

\section{Address for correspondence}

\section{Maria Karidakis}

The University of Melbourne

14 Prior Court

Delahey, Victoria 3037

Australia

m.karidakis@unimelb.edu.au

https://orcid.org/oooo-0002-1600-0027 


\section{Publication history}

Date received: 19 August 2019

Date accepted: 30 April 2020

Author Queries

- Please provide a complete reference for the citation '(Browne \& Varcoe, 2006)' in this article.

- Browne, A. J., \& Varcoe, C. (2006). Critical cultural perspectives and health care involving Aboriginal peoples. Contemporary Nurse, 22(2), 155-168.

- Please provide a citation for the reference id "CITo015 (Browne, J., D'Amico, E., Thorpe, $S_{\text {., }}$ \& Mitchell, C. (2014)), CIToo63 (Varcoe, C., \& Browne, A. (2006))" since citation is missing in the article. 


\section{University Library}

\section{- M M I N E R VA A gateway to Melbourne's research publications}

Minerva Access is the Institutional Repository of The University of Melbourne

Author/s:

Karidakis, M

Title:

Interpreter and Aboriginal Liaison Officer identity construction and positioning

Date:

2021-07-01

Citation:

Karidakis, M. (2021). Interpreter and Aboriginal Liaison Officer identity construction and positioning. Narrative Inquiry, 31 (2), pp.311-337. https://doi.org/10.1075/ni.19090.kar.

Persistent Link:

http://hdl.handle.net/11343/274298 